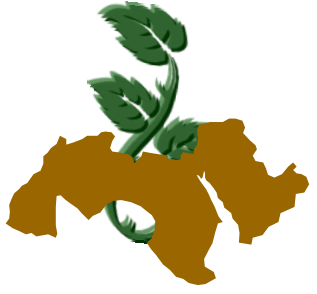

Arab Univ.

J. Agric. Sci., Ain Shams Univ., Cairo, 18(1), 221-226, 2010

\title{
TOLERANCE OF HONEY BEE COLONIES TO VARROA DESTRUCTOR (ANDERSON AND TRUEMAN) AND THE ECONOMIC THRESHOLD OF THE PARASITE IN THE CENTRAL REGION OF KINGDOM OF SAUDI ARABIA
}

\author{
Ali ${ }^{1}$, M.A.M. \\ 1- Department of Plant Protection, Faculty of Agriculture, Ain Shams University, Cairo, Egypt \\ Present Position and Address: Honey Bee Expert for Arab Organization for Agricultural \\ Development, League of Arab States, Ministry of Agriculture, Riyadh, K.S.A.
}

Keywords: Honey bees, Apis mellifera, Varroa destructor, Infestation levels, Economic threshold

\section{ABSTRACT}

Experiments were carried out on honey bee colonies (Apis mellifera) during the winter of 2008 and spring of 2009 using colonies wintered with five levels of varroa infestation $(0.0,3.8,9.0,13.1$ and $22.9 \%$ ) in the Central Region of the kingdom of Saudi Arabia. The goal of the present work is to determine varroa treatment thresholds and colony collapse level. Response variables examined included varroa mite infestation level (\%), $\mathrm{cm}^{2}$ of brood number of frames of brood, number of frames covered with adult honey bees and mites recovered on sticky boards. The data obtained reveled that no significant differences were noticed in $\mathrm{cm}^{2}$ of brood, number of frames of brood, and number of frames of bees in colonies (range of 0.0 to $9.0 \%$ varroa infestation or $0.0-0.9 \mathrm{mites} / \mathrm{bee}$ ) Colonies with $13.1 \%$ infestation ( 0.13 mites/bee) exhibited a significant reduction in all measures of performance. The present results suggested that honey bee colonies can tolerate a level of $9.0 \%$ varroa infestation ( 0.9 mites/bee) during the winter without evidence of colony injury. It also suggested that $13.1 \%$ infestation $(0.13$ mites/bee $)$ is the colony collapse or economic injury threshold in the Central Region of the Kingdom of Saudi Arabia. Also colonies with 12.3 or more mites falling on sticky boards after 48-hour period were likely to have lower populations of bees and brood the following spring.

\section{INTRODUCTION}

Fluvalinate has been used to control varroa mites for approximately 20 years. This single treatment option has become a matter of concern in light of recent evidence indicating the Varroa destructor populations in Europe (Lodesani et al 1995; Colin et al 1997; Trouiller, 1998); UK (Helen et al 2002) and the USA (Baxter et al 1998; Elzen et al 1999) have developed resistance to Apistan $\AA^{\circledR}$. In addition to the risks of contaminating hive products, especially honey (Gamber, 1990; Slabezki et al 1991; Wallner, 1995) and wax (Slabezki et al 1991; Wallner, 1995), residue problems provide additional incentive to seek alternative control strategies based on natural products and integrated pest management to reduce the risk of hive product contamination. The detection of resistance to miticides used to control varroa (Lodesani et al 1995 and Baxter et al 1998) supports the need to develop economic thresholds to reduce the frequency of miticide treatments whenever possible (Hood and Delaplane, 2001). Delaplane et al (2005) conducted a study on the integrated pest management of Varroa destructor to reduce colony mite levels and the frequency of treatment. Le Conte et al (2007) compared the mortality of collected Varroa surviving bee (VSB) stock with that of miticide-treated Varroasusceptible colonies. Varroa infestation did not induce mortality in the VSB colonies. Their results concluded that untreated local honey bee colonies can survive the mite, which may be the basis for integrated Varroa management. 
Ali (2001) in USA found that infestation levels of varroa mites ranging from 0.0 to $12 \%$ or $0.0-$ $0.12 \mathrm{mites} / \mathrm{bee}$ did not significantly reduce the $\mathrm{cm}^{2}$ of brood, number of frames of brood, and frames covered with bees. $\mathrm{He}$ also concluded that $12 \%$ infestation was the economic threshold level for varroa mite. In temperate regions, De Jong (1997) found that mortality in untreated $A$. mellifera colonies was nearly $100 \%$ and (Korpela et al 1992 and Fries, 1993) concluded that mite numbers in temperate colonies increase 10 to 100 fold per year. Mite emigration (Dinar and Effart, 1990), the amount of brood, and the length of the brood rearing season (Fries et al 1994), climatic differences (Hood and Delaplane, 2001) may affect the rate of varroa population increase. According to Gatien and Currie (1995) infestation levels of $0.03-0.07$ mites/bee in early spring had a significant economic impact on honey production. High colony mortality in autumn of the same year followed a spring infestation of 0.07 mites/bee. Phibbs (1996) found that colonies with varroa infestation levels greater than 0.01 mites/bee in autumn ( $>2$ mites/200 bees) suffered the highest winter mortality. In Great Britain, Martin, (1998) suggested that a colony will not collapse from varroa during winter if the mite population is below 2,500 in August or September.

The aim of this study is to establish an economic threshold level for varroa mites in honey bee colonies in the Central Region of the kingdom of Saudi Arabia to reduce the frequency of acaricide treatments and to minimize the risks of hive products contamination as well as to decrease the expense and labor that use for varroa treatments.

\section{MATERIALS AND METHODS}

The present work was conducted during the winter of 2008 and spring 2009 on Carniolan honey bee colonies (Apis mellifera) wintered with five levels of varroa infestation in the Central Region of Saudi Arabia which were naturally infested with varroa mite. Samples of adult worker bees were collected (300 bees/125 ml jar containing 70\% alcohol as described by Shimanuki and Knox (2000) and the infestation level was estimated. Accordingly, honey bee colonies were grouped into five categories each contained 10 colonies as replicates:

The first group: Contained colonies with no detectable mites.

The second group: Contained colonies with 1-5\% varroa infestation $(0.01-0.05$ mites/ bee $)$, with a mean $3.8 \pm 0.29 \%(0.04$ mites $/$ bee $)$.
The third group: Contained colonies with 6-10\% varroa infestation $(0.06-0.1$ mites/bee $)$, with a mean of $9.00 \pm 0.35 \%$ ( 0.09 mites $/$ bee $)$.

The fourth group: Contained colonies with 11-15\% varroa infestation $(0.11-0.15$ mites/bee $)$, with a mean $13.1 \pm 0.44 \%$ ( 0.13 mites $/$ bee $)$.

The fifth group: Contained colonies with 16-25\% varroa infestation $(0.16-0.25$ mites/ bee $)$, with a mean of $22.9 \pm 0.86 \%$ ( 0.22 mites $/$ bee $)$.

All experimental colonies were located at Queen Rearing and Honeybee Nuclei Production Station, Agricultural Extension Department, Ministry of Agriculture, at the Nmar Valley, Riyadh, Kingdom of Saudi Arabia. On November 15, 2008, mite infestation levels were estimated.

\section{Strength of the honeybee colonies}

The following parameters were studied: $\mathrm{Cm}^{2}$ of brood, number of frames of brood and number of frames covered with adult honey bees from both sides. The three measures of strength were determined on April 21, 2009. The brood areas were measured for both sides of each brood frame in all the experimental colonies, the brood areas in each colony were counted and recorded. The number of frames of brood and frames covered with honey bees were recorded visually inspecting the colonies for each frame (Ali, 2001).

\section{Mites caught on sticky boards}

On April 25, 2009; sticky boards (a peace of map paper $38 \times 31 \mathrm{~cm}$ covered with medical Vaseline) were inserted in all the colonies of the five groups. After 48 hours, sticky boards were removed and mites were counted.

\section{Experimental design and analysis}

The experimental design was a completely randomized design. Results were analyzed using SAS (SAS Institute, 1985). The general linear modules procedure to test for differences (alpha= $0.05)$ was applied and the least significant differences mean separation test was used.

\section{RESULTS AND DISCUSSION}

\section{Strength of honey bee colonies infested with different varroa levels}

Data given in Table (1) show the mean percentages of varroa infestation per $\mathrm{cm}^{2}$ of brood, frames of brood and frames covered with adult honey bees. Mean values of varroa infestation were $0.00,3.8,9.0,13.1$ and $22.9 \%$ in the five groups with significant differences among them. 
Table 1. Square centimeters of brood, frames of brood and frames of bees infested with different levels of varroa mites in November (Mean \pm S.E)

\begin{tabular}{|l|c|c|c|c|}
\hline \multicolumn{1}{|c|}{ Group } & $\begin{array}{c}\text { Infestation levels } \\
\text { (\%) }\end{array}$ & $\begin{array}{c}\text { Square centimeters } \\
\text { of brood }\end{array}$ & Frames of brood & Frames of bees \\
\hline I & $0.0 \pm 0.0 \mathrm{e}$ & $854.200 \pm 17.904 \mathrm{a}$ & $3.350 \pm 0.150 \mathrm{a}$ & $8.750 \pm 0.201 \mathrm{a}$ \\
II & $3.841 \pm 0.295 \mathrm{~d}$ & $806.000 \pm 14.526 \mathrm{a}$ & $3.450 \pm 0.138 \mathrm{a}$ & $8.050 \pm 0.090 \mathrm{a}$ \\
III & $8.929 \pm 0.357 \mathrm{C}$ & $787.200 \pm 13.584 \mathrm{a}$ & $3.350 \pm 0.150 \mathrm{a}$ & $7.925 \pm 0.190 \mathrm{a}$ \\
IV & $13.065 \pm 0.449 \mathrm{~b}$ & $435.800 \pm 10.655 \mathrm{~b}$ & $2.000 \pm 0.000 \mathrm{~b}$ & $4.100 \pm 0.100 \mathrm{~b}$ \\
V & $22.937 \pm 0.864 \mathrm{a}$ & $422.800 \pm 7.772 \mathrm{~b}$ & $1.700 \pm 0.082 \mathrm{~b}$ & $3.950 \pm 0.050 \mathrm{~b}$ \\
\hline F value & 139.32 & 6.25 & 5.70 & 6.15 \\
\hline L.S.D & 1.373 & 68.000 & 0.339 & 0.835 \\
\hline
\end{tabular}

Means in a column followed by different letters were significantly different (least significant difference $P=.05$ )

These data also show that there were no significant differences in the amount of brood noticed among the first three groups, however these three groups significantly differed from groups four and five. The square centimeters of brood averaged $854.2,806.0$ and 787.2 in the first three groups, respectively. Infestation level significantly reduced the square centimeters of brood in group four and five, being (435.80 and 422.80), respectively without significant differences between them.

There were no significant differences in the number of brood frames among the first three groups; being $3.35,3.45$ and 3.35 , respectively. The mean number of brood frames in groups four and five were 2.00 and 1.70 , respectively which was significantly lower than that found in the other groups.

Data given in Table (1) show that no differences in the number of frames covered with bees were found in the first three levels of varroa infestation. The mean numbers of frames covered with adult bees from both sides were 8.70, 8.05 and 7.90 in the first three levels, respectively. However, 4.1 and 3.9 frames were recovered in group four and five, respectively, which were significantly lower than those found in the first three groups, without significant differences between them.

\section{Relationship between varroa infestation levels and mites recovered on sticky boards}

Data obtained in Table (2) show the relationship between the infestation levels and mites recovered on sticky boards in the experimental colonies. The mean number of mites recovered on sticky boards differed among the three groups of colonies with detectable mites. Colonies in level five mites had a significantly higher number of mites recovered on sticky boards than colonies in the other groups. The mean numbers of mites recovered on sticky boards were 1.8, 6.6, 12.3 and 19.9 in second, third, fourth and fifth infestation levels, respectively. These results suggest that colonies with 12.3 or more mites falling on sticky boards after 48-hour period were likely to suggest lower populations of bees and brood in the following spring.

Table 2. Mean number of varroa mites recovered on sticky boards in colonies with five infestation levels after leaving them 48 hours (Mean \pm S.E)

\begin{tabular}{|l|c|c|}
\hline Group & $\begin{array}{c}\text { Infestation levels } \\
(\%)\end{array}$ & $\begin{array}{c}\text { Mean number of } \\
\text { varroa mites } \\
\text { recovered on } \\
\text { sticky boards }\end{array}$ \\
\hline I & $0.00 \pm 0.00 \mathrm{e}$ & $0.00 \pm 0.00 \mathrm{e}$ \\
II & $3.841 \pm 0.295 \mathrm{~d}$ & $1.8000 \pm 0.327 \mathrm{~d}$ \\
III & $8.929 \pm 0.357 \mathrm{c}$ & $6.6000 \pm 0.267 \mathrm{c}$ \\
IV & $13.0654 \pm 0.449 \mathrm{~b}$ & $12.3000 \pm 0.448 \mathrm{~b}$ \\
V & $22.937 \pm 0.864 \mathrm{a}$ & $19.9000 \pm 0.640 \mathrm{a}$ \\
\hline F value & 139.32 & 3.15 \\
\hline L.S.D & 1.373 & 1.131 \\
\hline
\end{tabular}

Means in a column followed by different letters were significantly different (least significant difference $P=.05$ ) 


\section{DISSCUSSION}

The Central Region of Saudi Arabia has high temperature and dry weather conditions in summer. The temperature often exceeds $45^{\circ} \mathrm{C}$ and numerous honey bee colonies could not survive during summer season without continuous supplementary feeding (Al-Ghamdi, 2002 and Ali, 2007). The productivity of honey bee colonies throughout the year is influenced by different factors, such as queen age and egg laying capacity, colony population and available empty combs as well as temperature and supply of both pollen and nectar (Corbet et al 1993 and Abdella, 1996).

Spring brood and bee populations in colonies wintered with five levels of varroa infestation (mites/bee) during the winter of 2008 and spring 2009 were examined. Results reveled that no significant differences were noticed in $\mathrm{cm}^{2}$ of brood, number of frames of brood and number of frames covered with adult bees in colonies ranged between 0.0 to $8.9 \%$ varroa infestation. Colonies with $13.1 \%$ infestation exhibited a significant reduction in all three measures of performance. This study suggests that varroa infestation levels up to $9.0 \%$ ( 0.9 mites/bee) will not affect wintering or colony performance the following spring. This level of infestation is considered as an economic threshold level for varroa mite in the apiaries under Central Region of Saudi Arabia conditions. These findings agree with data obtained by Gatien and Currie's (1995) who reported that infestation levels of 0.03 -0.07 mites/bee (3-7\% infestation) in the spring resulted in high winter mortality. Also, Fries (1993) estimated a 10-fold increase in mite infestation level during the summer. He suggested that high colony mortality will occur. Martin, (1998) suggested that colonies would collapse in winter when mite populations exceed 2,500 per colony. His results of this study do not support the findings of Ali, (2001), who found that honey bee colonies can tolerate a level of 0.12 mites/bee (12\% infestation) during the winter without evidence of colony injury and Delaplane and Hood, (1997), who found that acaricide treatment was justified in late season when mite populations exceed $12 \%$ with $1,825 \mathrm{~cm}^{2}$ of brood. Phibbs, (1996) reported that colonies with as few as $0.01 \mathrm{mite} / \mathrm{bee}$ (1\% infestation) in the fall exhibited high winter mortality and much lower economic threshold than reported in this study.

The present work suggests that honey bee colonies in Saudia Arabia can tolerate a level of $9.0 \%$ varroa infestation (0.09 mites/bee) during the winter without evidence of colony injury. It also sug- gested that $13.1 \%$ infestation $(0.13$ mites/bee) could result in colony collapse under Central Region of Saudi Arabia conditions.

Beekeepers should carefully consider the timing of acaricide treatments for the control of varroa mites. Unnecessary treatments may lead to increased risks of contaminating hive products, especially honey and bee wax accelerated mite resistance to the acaricides and extra expense and labor to the beekeepers. The goal should be to avoid treatment at low tolerable mite levels and to intervene with an acaricide only when higher varroa levels are reached. The optimum treatment time is when the varroa mite infestation reaches the "treatment threshold." This is the density at which control measures should be applied to prevent the mite population from reaching the colony collapse level (Hood and Delaplane, 2001). Therefore, the present data recommended that beekeepers in the Central Region of Saudi Arabia sample their colonies to estimate varroa infestation levels by collecting about 300 bees in $125 \mathrm{ml}$ jar containing $70 \%$ alcohol to estimate infestation levels. Beekeepers should not treat their colonies if the infestation level is below $9 \%$ ( 0.09 mite/bee). This level is considered the tolerance level for varroa mites for the Central Region of Saudi Arabia. Colonies with a varroa infestation level of $13.1 \%$ $(0.13 \mathrm{mites} / \mathrm{bee})$ is considered the expected level for collapse of hives in the Central Region of Saudi Arabia. Beekeepers can also use sticky boards to detect varroa mites in their colonies, if the mean number of mites falling on sticky boards reached more than 6.6 mites per colony, they should treat promptly.

\section{ACKNOWLEDGMENTS}

I wish to express my sincere thanks to Dr. Marion D. Ellis, Professor of Entomology, Department of Entomology, University of Nebraska, Lincoln, USA for reviewing the manuscript.

\section{REFERENCES}

Abdella, F. (1996). Relationship between age of honeybee queen and its egg productivity. $1^{\text {st }}$ Conf. Arab Beekeepers Union, Beirut, Lebanon, pp. 19-24.

Al-Ghamdi, A. (2002). The effect of pollen supplementary feeding on some activities of honeybee colonies during summer season in Riyadh, Saudi Arabia. Saudi J. Biol. Sci., 9(2): 85-94. 
Ali, M.A.M. (2001). Biological and Ecological Studies on Certain Pests of Honey Bees, pp. 75-90. Ph.D. Thesis, Fac. of Agric. Ain Shams Univ., Cairo, Egypt.

Ali, M.A.M. (2007). Effect of supplemental feeding on brood production and population development of honey bee (Apis mellifera jementica). Minufia $\mathbf{J}$. Agric. Res., 32(3): 915-932.

Baxter, J.R.; F. Eischen; J. Pettis; W.T. Wilson and H. Shimanuki (1998). Detection of fluvalinateresistant varroa mites in U.S. honey bee. Am. Bee J., 138: 291-295.

Colin, M.E.; R. Vandame; P. Jourdan and S. Pasquale (1997). Fluvalinate-resistance of Varroa jacobsoni Oudemans (Acari:Varroidae) in Mediterranean apiaries of France. Apidologie, 28: 375 384.

Corbet, S.A.; M. Fussell; R. Ake; A. Fraser; C. Gunson; A. Savage and K. Smith (1993). Temperature and pollination activity of social bee. Ecol. Entomol., 18(1): 17-30.

De Jong D. (1997). Mites: Varroa and Other Parasites of Brood, (c.f. Morse, R.A. and R. Nowogrodzki (eds.), Honey Bee Pests, Predators, and Diseases. $3^{\text {rd }}$ Ed. pp. 279-327. Cornell University Press, Ithaca, NY).

Delaplane K.S. and W.M. Hood (1997). Effects of delayed acaricide treatment in honey bee colonies parasitized by Varroa jacobsoni and a late season treatment threshold for the southeastern USA. J. Apic. Res., 36: 125-132.

Delaplane K.S.; J.A. Berry; J.A. Skinner; J.P. Parkman and W.M. Hood (2005). Integrated pest management against Varroa destructor reduces colony mite levels and delays treatment threshold. J. Apic. Res., 44(4): 157-162.

Dinar, A. and C. Effart (1990). Economic threshold for a pathogenic disease: the case of varroasis in bee. Agricultural Systems, 32: 13-25.

Elzen, P.J.; J.R. Baxter; M. Spivak and W.T. Wilson (1999). Amitraz resistance in Varroa: new discovery in North America. Am. Bee J., 139: 362367.

Fries, I. (1993). Varroa in Cold Climates, In: Matheson, A. (ed.). Living with Varroa, pp. 3748. International Bee Research Association, Cardiff, England.

Fries, I.; S. Camazine and J. Sneyd (1994). Population dynamic of Varroa jacobsoni: A model and review. Bee World, 75: 5-28.

Gamber, W.R. (1990). Fluvalinate scare should serve as warning. Am. Bee J., 130(10): 629-632.
Gatien, P. and R.W. Currie (1995). Effectiveness of control measures for the Varroa mites. Canad. Honey Council Res. Sym. Proc., Manitoba, Canada, pp. 3-8.

Helen, M.T.; M.A. Brown; R.F. Ball and M.H. Bew (2002). First report of Varroa destructor resistance to pyrethroids in the UK. Apidologie, 33: 357-366.

Hood, W.M. and K.S. Delaplane (2001). Treatment thresholds for varroa mites. In: Mites of the Honey Bee, pp. 156-201. Dadant and Sons Inc., Hamilton, Illinois, USA.

Korpela, S.; A. Aarhus; I. Fries and H. Hansen (1992). Varroa jacobsoni Oud. In cold climates; population growth, winter mortality and influence on the survival of honey bee colonies. J. Apic. Res., 31: 157-164.

Le Conte, Y.; G. de Vaublanc; D. Crauser; F. Jeanne; Jean-Claude Rousselle and Jean-Marc Bécar (2007). Honey bee colonies that have survived Varroa destructor. Apidologie, 38: 566572.

Lodesani, M.; M. Colombo and J. Sneyd (1995). Ineffectiveness of Apistan treatment against the mite Varroa jacobsoni Oud., in several districts of Lombardy (Italy). Apidologie, 26: 67-72.

Martin, S.J. (1998). Varroa jacobsoni: monitoring and forecasting mite populations within honey bee colonies in Britain. Ministry of Agriculture, Fisheries and Food in Association with the Central Science Laboratory. Leaflet PB 3611, 12 pp. York, England.

Phibbs, A. (1996). Three years survey of Varroa mite and tracheal mite infestations of honey bees in Wisconsin. Am. Bee J., 136: 589-592.

SAS Institute (1985). SAS/STAT Guide for Personal Computers, Version $6^{\text {th }}$ Ed. SAS Institute, Cary, NC.

Shimanuki, H. and D.A. Knox (2000). Diagnosis of honey bee diseases. USDA, ARS, Agriculture Handbook No. 690.

Slabezki, Y.; H. Gal and Y. Lensky (1991). The effect of fluvalinate application in bee colonies on population levels of Varroa jacobsoni and honey bee (Apis mellifera L.) and on residues in honey and wax. Bee Sci., 1: 189-195.

Trouiller, J. (1998). Monitoring of Varroa jacobsoni resistance to pyrethroids in Europe. Apidologie, 29: 537-546.

Wallner, K. (1995). The use of varroacides and their influence on the quality of bee products. Am. Bee J. 135(12): 817-821. 